\title{
USING GROUND BASED GEOPHYSICS TO EVALUATE HYDROGEOLOGIC EFFECTS OF SUBSURFACE DRIP IRRIGATION SYSTEMS USED TO MANAGE PRODUCED WATER IN THE POWDER RIVER BASIN, WYOMING
}

\author{
James I Sams III, National Energy Technology Laboratory, Pittsburgh, Pennsylvania \\ Brian A. Lipinski, Department of Geology and Planetary Sciences, University of Pittsburgh, \\ Pittsburgh, Pennsylvania \\ Garret Veloski, National Energy Technology Laboratory, Pittsburgh, Pennsylvania
}

\begin{abstract}
The U.S Department of Energy's National Energy Technology Laboratory has been evaluating various geophysical methods for site characterization regarding environmental issues associated with fossil fuels including produced water management. A relatively new method of managing produced water from coal bed natural gas production is through subsurface drip irrigation. This system involves disposing the produced water near the bottom of the root zone in agricultural fields, which would provide a beneficial use of this resource. The focus of this paper is to present results from a pre-injection geophysical survey for site assessment and background data. A pre-construction survey of approximately $1.2 \mathrm{~km}^{2}$ was completed in June 2007 using a Geophex GEM-2 broadband sensor over six fields along the Powder River floodplain. Quality assurance measures included drift checks, duplicate line surveys, and repeat field surveys using the Geometrics OhmMapper instrument. Subsequent surveys will be completed once the system is installed and operational. Geophysical inversion models were completed to provide a detailed cross-section of the subsurface geoelectrical structure along each line. Preliminary interpretations reveal that the subsurface conductivity distribution correlates to geomorphologic features.
\end{abstract}

\section{Introduction}

Rapid development of coalbed natural gas (CBNG) in the Powder River Basin (PRB) of Wyoming has occurred since 1997 focusing national attention on produced water management (BLM, 2003a, b; De Bruin et al., 2004; DOE, 2003; Frost et al., 2002; Ganjegunte et al., 2005; Stearns et al., 2005). CBNG is a continuous gas accumulation because there is no readily definable hydrocarbon-water boundary (Flores et al., 2004). Methane is primarily adsorbed to coal cleats, but it can also occur as free gas within pores or as dissolved gas in porewater (Ayers, 2002; De Bruin et al., 2004; Flores et al., 2004; Yee et al., 1993). To develop this resource, the hydrostatic pressure must be reduced by removing groundwater from the coalbed causing methane to desorb, flow to the extraction well, and then rise to the surface for distribution. PRB wells have some of the highest water/gas production ratios of current CBNG fields. Each PRB well produces 1.9 barrels (bbls) of water per 1000 cubic feet (MCF) gas, while San Juan Basin CBNG wells produce approximately 0.031 bbls of water per MCF gas (DOE, 2003). Since development began in Wyoming, over 4.1 Bbbls of water have been produced from approximately 22,000 wells (WOGCC, 2006). There are expected to be approximately 65,000 additional wells in the basin by the end of gas production (BLM, 2003a). 
CBNG water management is an important issue because groundwater is heavily used for domestic, agricultural, and industrial purposes. Improper disposal may degrade groundwater quality because coalbed aquifer water is moderately saline (TDS $<5,000 \mathrm{mg} / \mathrm{L}$ ) and characteristically sodic (Bartos and Ogle, 2002; Rice et al., 2005; Rice et al., 2000) and may dissolve vadose zone salts contained within the semiarid soils. Past disposal methods included direct surface discharge, containment impoundments, land application disposal, and reinjection (BLM, 2003a). However, these applications provide minimal beneficial use of the produced water.

Recently, subsurface drip irrigation (SDI) has gained popularity as a disposal method. An SDI system is constructed by installing perforated polyethylene tubing (called laterals) approximately 7 to $19 \mathrm{~cm}$ below the ground surface, near the bottom of the root zone. Each lateral is spaced approximately 15 to $24 \mathrm{~cm}$ apart. CBNG water is then pretreated according to its site specific chemistry and transported to field valves which release the water to multiple underground laterals. Water drains from the perforated laterals at a rate of 0.75 to 1.5 gallons per day year round (Beneterra, 2007). This style of irrigation is advantageous because it provides a beneficial use of water by increasing crop yields while preventing sodium accumulation in surface soils and maintaining viewscapes because there is limited surface disturbance (Beneterra, 2007).

The purpose of this study is to evaluate the efficacy of the electromagnetic (EM) induction method to investigate SDI disposal of produced water. In order to do this, we completed a detailed ground-based EM survey using a Geophex GEM2 prior to installation of the SDI system to provide baseline background information. The reliability for the GEM2 survey was checked by performing repeat lines and by using a Geometrics OhmMapper capacitively coupled resistivity system. Future work will include detailed soil sampling coupled with borehole geophysical measurements to evaluate the suitability of geophysical techniques to monitor CBNG disposal using SDI.

\section{Methods of Investigation}

\section{Geophysical Surveys}

The study site is located approximately $17 \mathrm{~km}$ south of Arvada, Wyoming within the Powder River Basin at the confluence of Crazy Women Creek and the Powder River (Figure 1). A preconstruction ground-based geophysical survey of a proposed $1.2 \mathrm{~km}^{2}$ SDI site was completed in several fields from June 3 to June 14, 2007. The survey will serve as a baseline for subsequent surveys designed to monitor the EM response resulting from CBNG water discharged through the SDI system. The survey was completed using a Geophex GEM2 instrument mounted on a sled constructed of PVC pipe. The sled was towed $10 \mathrm{~m}$ behind a utility vehicle guided by a differential GPS navigation system. Five frequencies were programmed into the instrument $(1530 \mathrm{~Hz}, 8250 \mathrm{~Hz}, 23070 \mathrm{~Hz}, 33030 \mathrm{~Hz}$, and $47970 \mathrm{~Hz}$ ). Data were collected in 5 fields (Figure 1) at a sampling rate of $10 \mathrm{~Hz}$ with $25 \mathrm{~m}$ line spacing, resulting in approximately 55 line $\mathrm{km}$ of data. Calibrations were completed by collecting data for approximately five minutes at a fixed location before, during, and after the surveys. Resulting inphase/quadrature responses were filtered using a 10 point along-line median filter, leveled using the calibration data, and converted into apparent conductivity $(\mathrm{mS} / \mathrm{m})$ values. A minimum curvature method was used to create a grid with a $5 \mathrm{~m}$ cell size. 


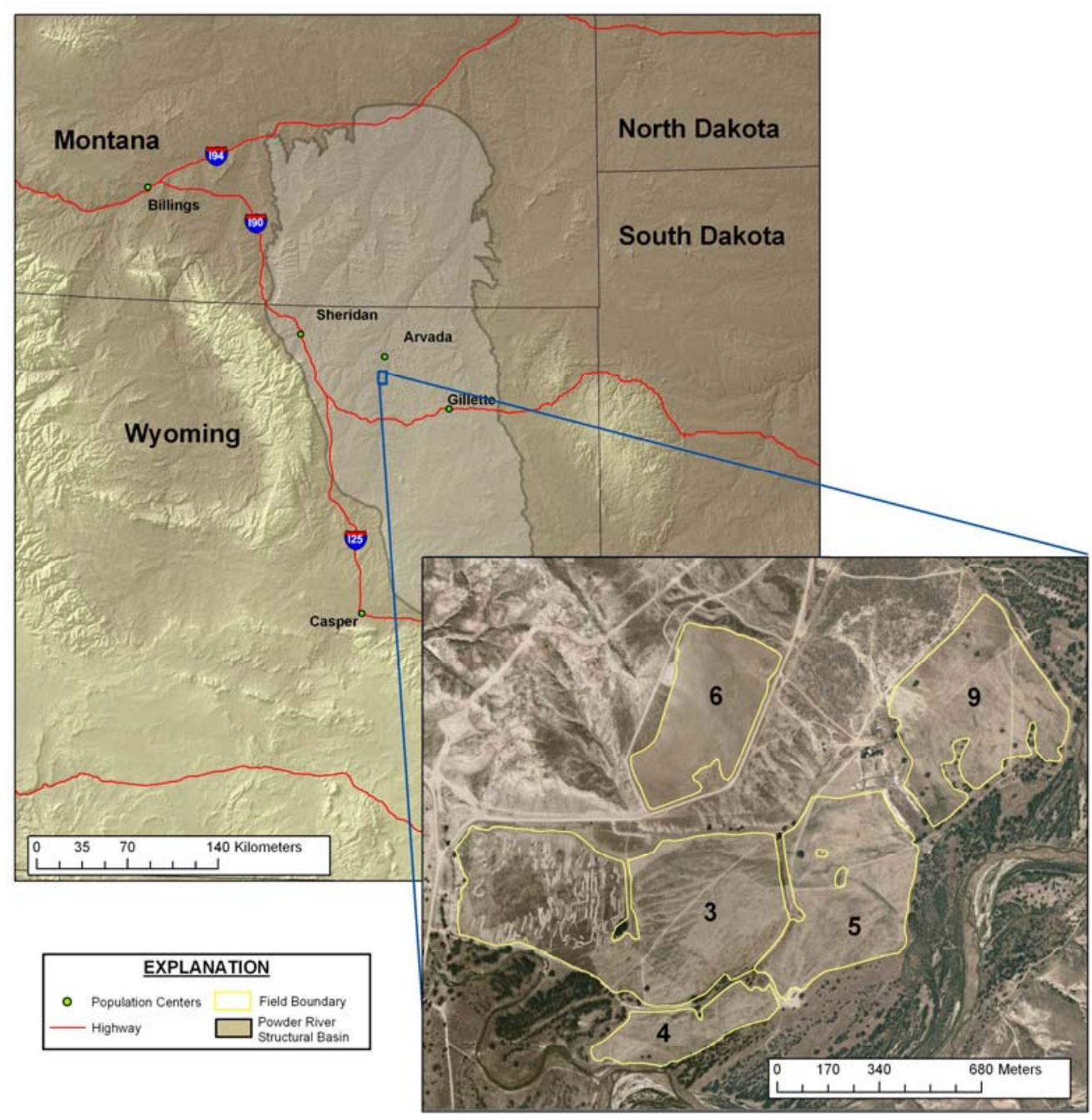

Figure 1: Location of project study area, Powder River Basin, Wyoming.

\section{Quality Assurance}

Care was taken to assure data quality and to check method reliability because this survey will provide baseline data prior to CBNG water disposal. Duplicate surveys were completed along selected lines in each field to evaluate the reproducibility of the GEM2 instrument. Field 4 was surveyed at $12.5 \mathrm{~m}$ line spacing to evaluate the effect of line spacing on calculated survey grids. Additionally, the Geometrics OhmMapper capacitively coupled resistivity system was used to confirm results from the GEM2 survey. The instrument was configured using an ungrounded dipole transmitter, 5 receivers, and a data logger. It was deployed in field 4 and field 6 (Figure 1) by retracing the GEM survey lines. Apparent resistivity was then calculated using the appropriate geometric factor for the antenna array and then converted into apparent conductivity data for comparison with the GEM2 data. 


\section{Data Inversion}

GEM2 data were inverted using EM1DFM (UBC-GIF, 2000) to determine the subsurface electrical conductivity distribution. EM1DFM is a layered earth inversion program that fits a modeled response to the data by minimizing an objective function. It is an Occam's inversion model in the sense that the objective function has a data misfit term and a model structure term (Constable et al., 1987; Farquharson et al., 2003; Sattel, 2005). Inputs required for the program are the inphase and/or quadrature response of the secondary magnetic field, transmitter/receiver geometry, instrument altitude, and data error (Farquharson et al., 2003). Data for each frequency were inverted to an earth model composed of 20 horizontal layers, each 1 m thick, with a starting conductivity model and reference conductivity model of $100 \mathrm{mS} / \mathrm{m}$. Inversions were completed using the fixed tradeoff parameter $(\beta)$ algorithm within EM1DFM using $\beta=10$ after trial inversions indicated this was the optimal value. The values of the smallest and flattest component of the model structure term were 0.01 and 1 respectively.

\section{Results}

\section{Quality Assurance Results}

The quality assurance tests revealed that the GEM2 data were reproducible and that $25 \mathrm{~m}$ line spacing is adequate. Duplicate surveys for field 3 and field 4 show that there is excellent agreement between the data (Figure 2). The apparent conductivity grid interpolated from the 47 $\mathrm{kHz}$ frequency data for the $12.5 \mathrm{~m}$ and $25 \mathrm{~m}$ line spacing shows that the major features are accurately delineated using the wider line spacing (Figure 3). Summary statistics are also very similar for the two datasets (figure 3). The OhmMapper data revealed some differences. In general, the locations of the conductive anomalies from the two methods are similar but their magnitudes are somewhat different (Figure 4).
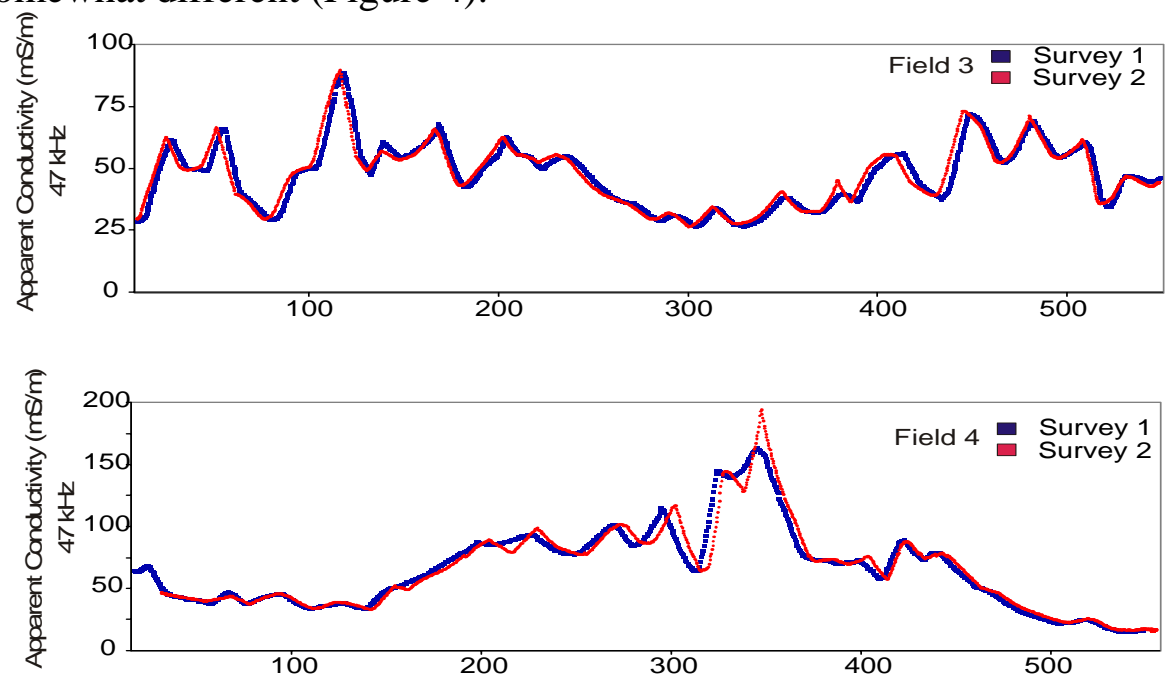

Figure 2: Results of duplicate GEM2 surveys for lines in field 3 and field 4. 

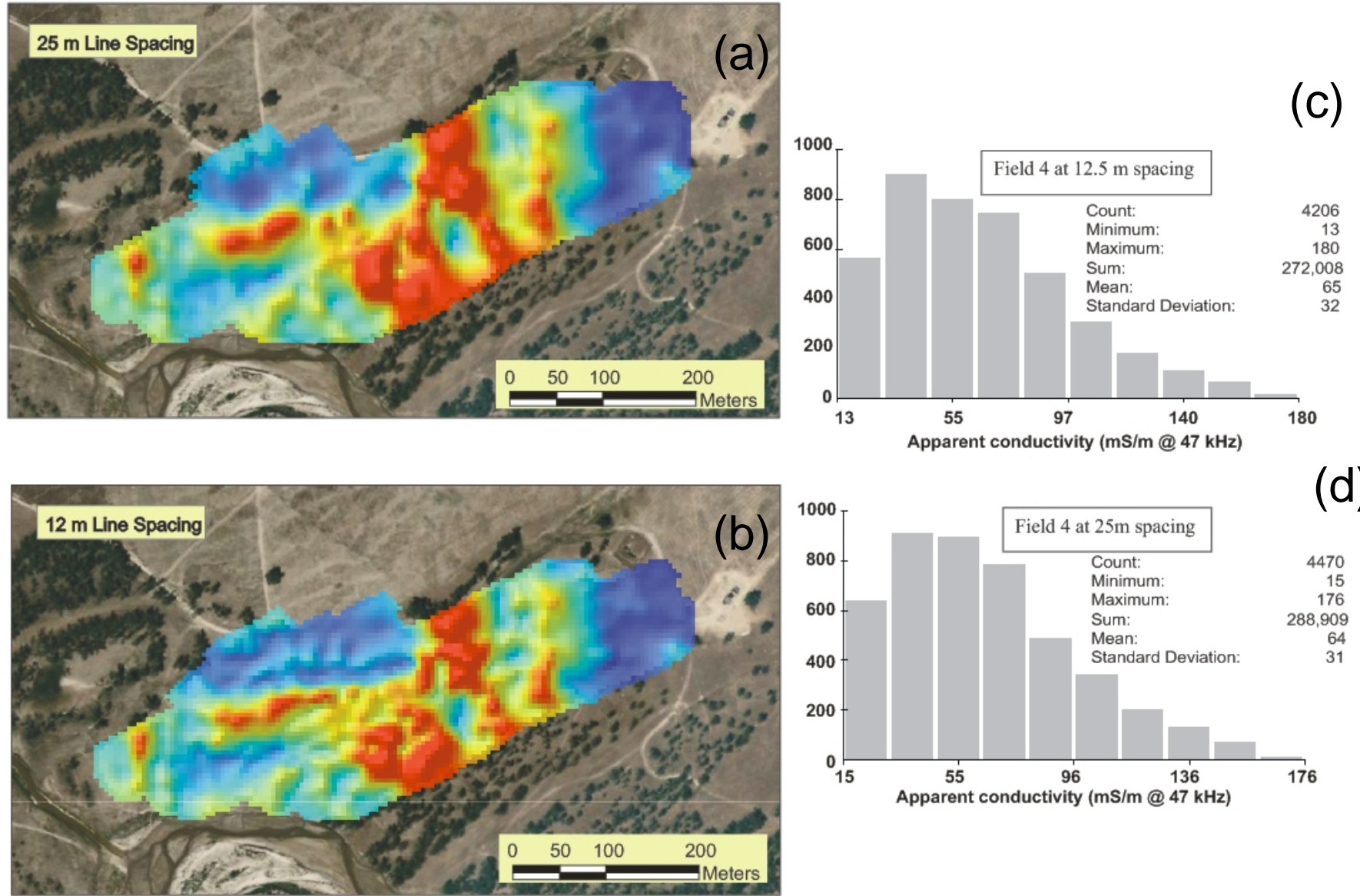

Figure 3: (a) Surface grid generated from $25 \mathrm{~m}$ line spacing (b) Surface grid generated from 12 $\mathrm{m}$ line spacing (c) Histogram and statistics from $12 \mathrm{~m}$ line spacing (d) Histogram and statistics from $25 \mathrm{~m}$ line spacing. 

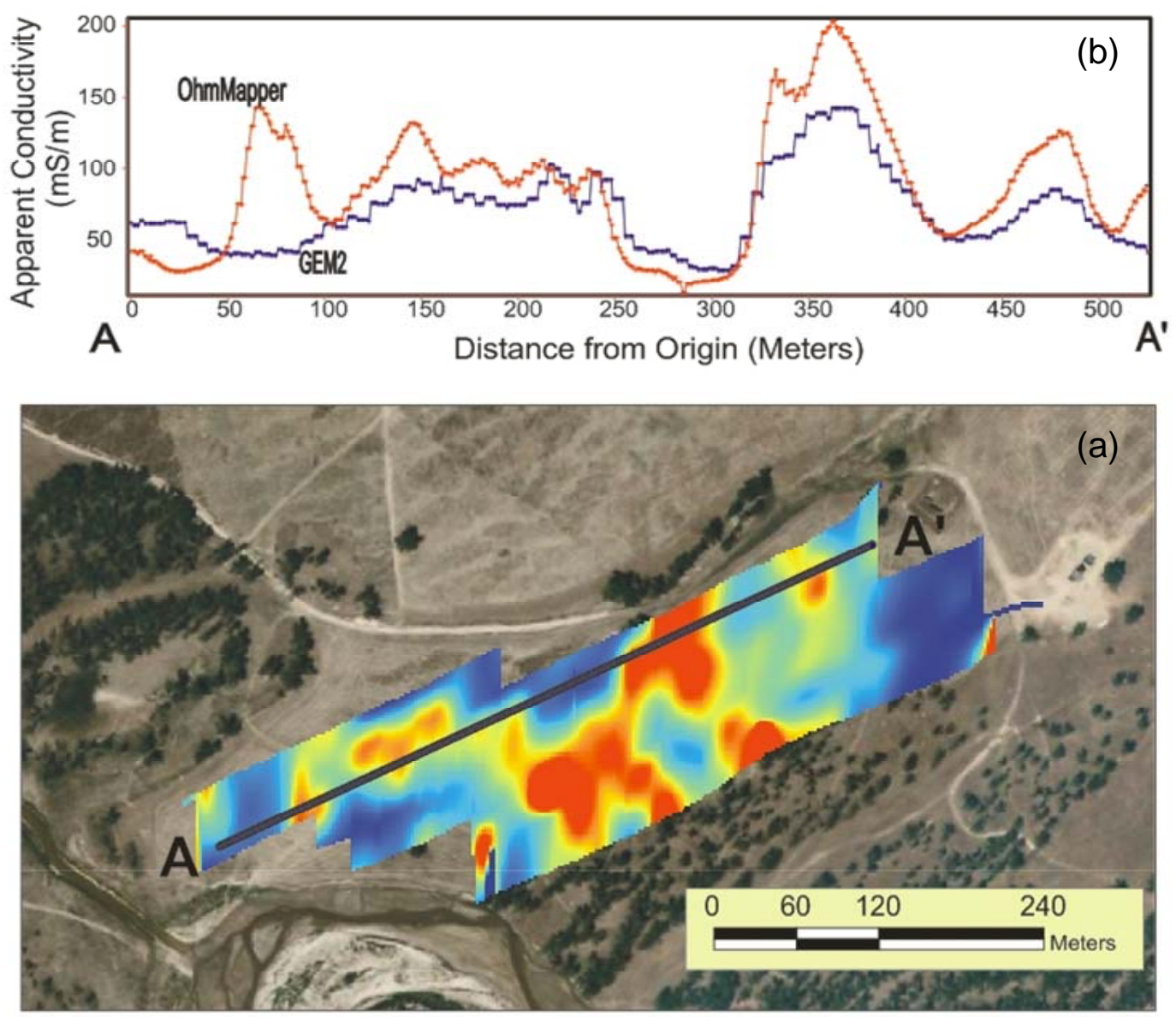

Figure 4: (a) Apparent conductivity surface derived from OhmMapper data at $12.5 \mathrm{~m}$ line spacing (b) Apparent conductivity profile comparing OhmMapper and GEM2 data.

\section{GEM Results}

The GEM survey provided a high resolution image of the subsurface electrical conductivity distribution in the fields where the SDI system will be installed (Figure 5). A large, broad, semi-circular anomaly occurs through field 3 and into field 5 . The anomaly appears to correlate to a paleochannel of the Powder River, but this is difficult to trace due to the cultivation. Conductivity-depth sections constructed from the EM1DFM inversions reveals that this conductive anomaly extends downward from the surface (Figure 6). The cause of this anomaly is currently unknown. However, detailed soil coring, chemical analyses, and groundwater studies are currently planned for the spring 2008, which will help to relate the geophysical response to real world parameters. The EM surveys can then be continued after the SDI system is installed to evaluate subsurface changes, if any, caused by produced water disposal. 


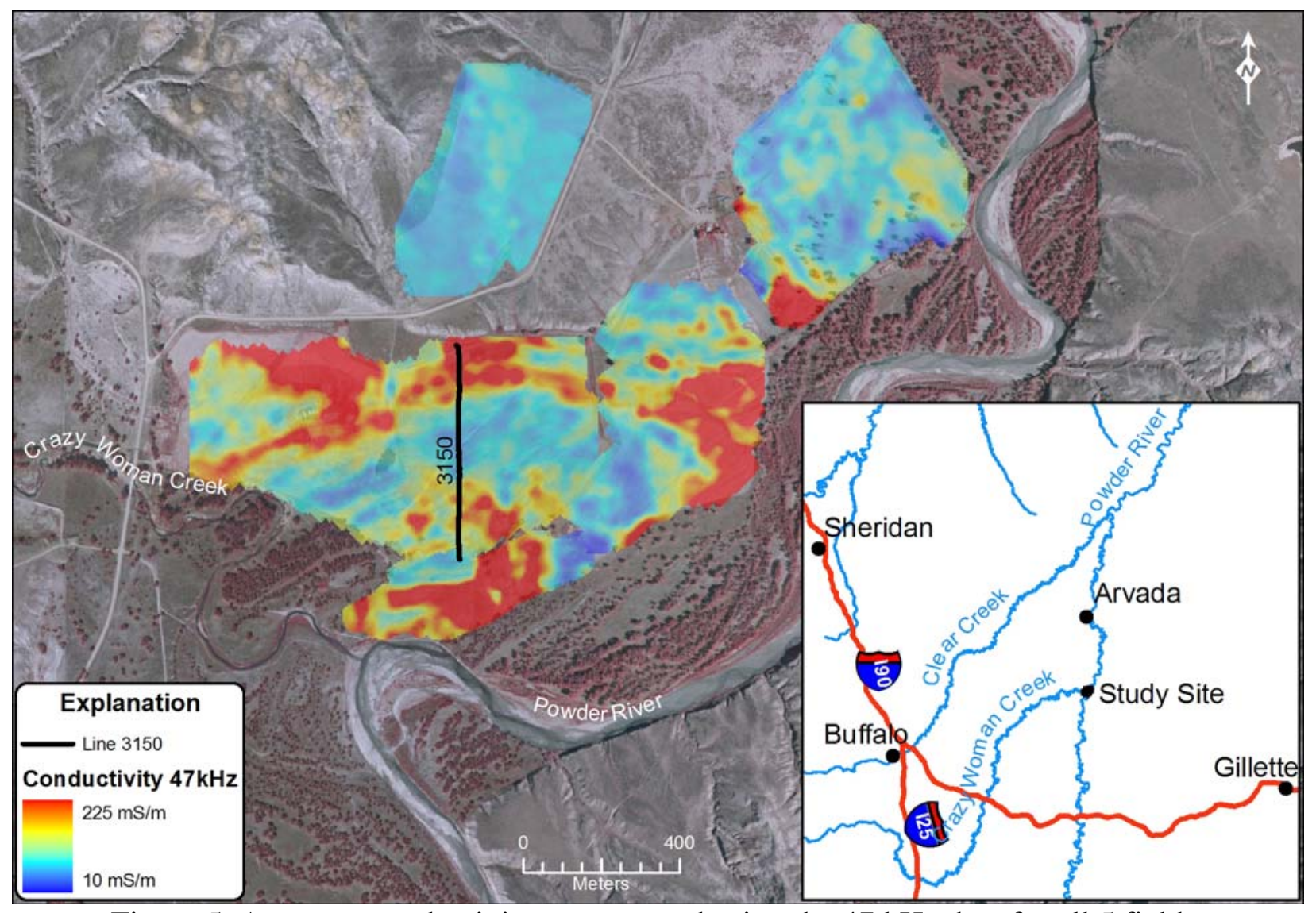

Figure 5. Apparent conductivity map created using the $47 \mathrm{kHz}$ data for all 5 fields.

A conductivity-depth section for line 3150 is presented in Figure 6.

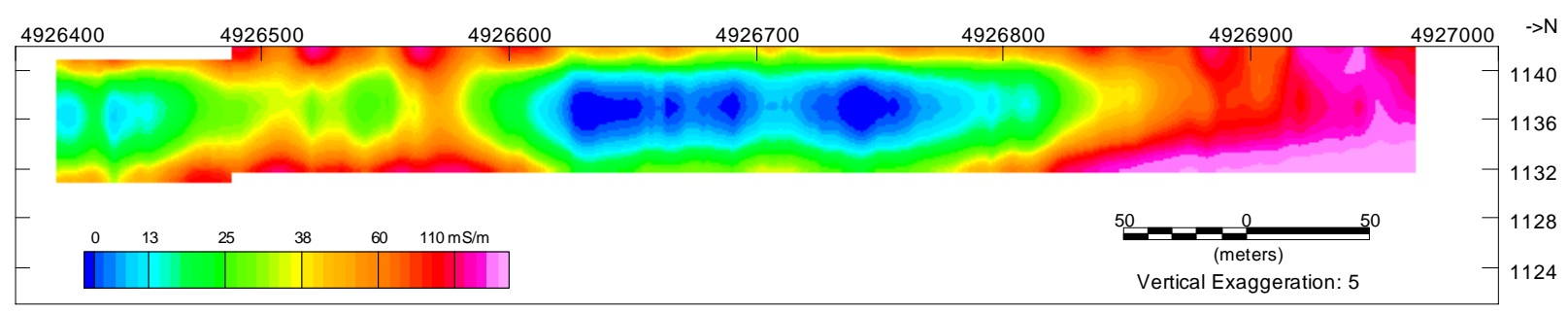

Figure 6. Subsurface electrical conductivity distribution derived through geophysical inversion of GEM2 multifrequency EM data. Only the top $10 \mathrm{~m}$ of the inversion is displayed. Line location is depicted in Figure 5.

\section{Conclusions and Future Work}

Subsurface drip irrigation (SDI) has recently been considered as an alternative means of managing produced water in an environmentally responsible and beneficial manner. This style of irrigation is capable of applying of 2 to 3 times more water on a particular site than traditional surface irrigation because water is introduced near the bottom of the root zone. 
The results of this investigation indicate that ground based geophysical instruments, such as the GEM2, provide a method for characterizing near surface electromagnetic properties. Duplicate surveys showed that field measurements were reproducible. A field test to evaluate the effects of line spacing indicated that 12.5 spacing did not substantially differ from the gridded surface generated from $25 \mathrm{~m}$ line spacing. The near surface soil properties as measured by EM are generally broad in nature within this study area. Future EM surveys designed to monitor the operation of the SDI system will likely be completed at $25 \mathrm{~m}$ line spacing. The GEM2 instrument also produced a similar EM response to data collected with the capacitively-coupled antenna array system used in the OhmMapper instrument.

These types of EM surveys should provide useful data to optimize the design of an SDI system. The potential for identifying subsurface soil and geologic conditions, such as the location of clay pans and clay lenses, could prove useful in locating and spacing subsurface SDI emitters. Furthermore, comprehensive site assessment before, during, and after application of CBNG produced water is critical for tracking salt movements and possible alterations in soil properties. Future work on this project is designed to assess site hydrology and soil conditions while the SDI system is in operation. Geophysical surveys, groundwater monitoring, and soil sampling will be included in future investigations of this site.

\section{References}

Bartos, T.T., and Ogle, K.M., 2002, Water quality and environmental isotopic analyses of ground-water samples collected from the Wasatch and Fort Union formations in areas of coalbed methane development - implications to recharge and ground-water flow, eastern Powder River Basin, Wyoming: U.S. Geological Survey Open File Report 02-4045.

Beneterra, 2007, Beneterra Subsurface Drip Irrigation for Dispersal of Coalbed Produced Water. http://www.beneterra.com/industries.htm\#coal.

BLM, 2003a, Final environmental impact statement and proposed plan amendment for the Powder River Basin oil and gas project: Bureau of Land Management Environmental Impact Statement WY-070-02-065.

—, 2003b, Final statewide oil and gas environmental impact statement and proposed plan amendment for the Powder River Basin and Billings resource management plans: Bureau of Land Management Environmental Impact Statement BLM/MT/PL-03/005.

Constable, S.C., Parker, R.L., and Constable, C.G., 1987, Occam's inversion; a practical algorithm for generating smooth models from electromagnetic sounding data: Geophysics, 52, 289-300.

De Bruin, R.H., Lyman, R.M., Jones, R.W., and Cook, L.W., 2004, Coalbed methane in Wyoming: Wyoming Geological Survey Information Pamphlet 7.

DOE, 2003, Coal Bed Methane Primer: New source of natural gas - environmental implications: National Energy Technology Laboratory National Petroleum Technology Office

Farquharson, C.G., Oldenburg, D.W., and Rough, P.S., 2003, Simultaneous 1D inversion of loop-loop electromagnetic data for magnetic susceptibility and electrical conductivity: Geophysics, 68, 1857-1869.

Flores, R.M., 1986, Styles of coal deposition in Tertiary alluvial deposits, Powder River Basin, Montana and Wyoming, in Lyons, P.C., and Rice, C.L., eds., Paleoenvironments and tectonic controls in coal-forming basins of the United States: Geological Society of America Special Paper 210, p. 105-122. 
Flores, R.M., Charpentier, R.R., Cook, T.A., Crovelli, R.A., Klett, T.R., Pollastro, R.M., and Schenk, C.J., 2004, Total petroleum system and assessment of coalbed gas in the Powder River Basin Province, Wyoming and Montana: U.S. Geological Survey Digital Data Series 0069-C.

Frost, C.D., Pearson, B.N., Ogle, K.M., Heffern, E.L., and Lyman, R.M., 2002, Sr isotope tracing of aquifer interactions in an area of accelerating coal-bed methane production, Powder River basin, Wyoming: Geology, v. 30, p. 923-926.

Ganjegunte, G.K., Vance, G.F., and King, L.A., 2005, Soil chemical changes resulting from irrigation with water co-produced with coalbed natural gas: Journal of Environmental Quality, v. 34, p. 2217-2227.

Leopold, L.B., and Miller, J.P., 1954, A postglacial chronology for some alluvial valleys in Wyoming: U.S. Geological Survey Water-Supply Paper 1261.

Lipinski, B.A., Sams, J., Smith, B.D., and Harbert, W., 2006, Using Helicopter EM Surveys to

Evaluate

Coalbed Natural Gas Produced Water Disposal in the Powder River Basin, Wyoming. Accepted for Geophysics.

Rice, C.A., Bartos, T.T., Brooks, M.H., Chong, G.W., Healy, R., Lipinski, B., McBeth, J., McKinley, M., Smith, B.D., and Smith, R.L., 2005, Coalbed natural gas development in the Powder River basin, WY and MT; impacts on land and water in a semiarid environment, Abstracts with Programs - Geological Society of America, Volume 37, p. 25.

Rice, C.A., Ellis, M.S., and Bullock, J.H., Jr., 2000, Water co-produced with coalbed methane in the Powder River basin, Wyoming; preliminary compositional data: U.S. Geological Survey Open-File Report 00-0372.

Ringen, B.H., and Daddow, P.B., 1990, Hydrology of the Powder River alluvium between Sussex, Wyoming, and Moorhead, Montana: U.S. Geological Survey Water-Resources Investigations 89-4002.

Sattel, D., 2005, Inverting airborne electromagnetic (AEM) data with Zohdy's method: Geophysics, 70, G77-G85.

Stearns, M., Tindall, J.A., Cronin, G., Friedel, M.J., and Bergquist, E., 2005, Effects of coal-bed methane discharge waters on the vegetation and soil ecosystem in the Powder River Basin, Wyoming: Water, Air, and Soil Pollution, v. 168, p. 33-57.

Tølbøll, R.J., and Christiansen, N.B., 2006, Robust 1D inversion and analysis of helicopter electromagnetic (HEM) data: Geophysics, v. 71, p. G53-G62.

UBC-GIF, 2000, EM1DFM: A Program Library for Forward Modelling and Inversion of Frequency Domain Electromagnetic Data over 1D Structures.

WOGCC, 2006, Wyoming Oil and Gas Conservation Commission Online Searchable Database: http://wogcc.state.wy.us/

Yee, D., Seidle, J.P., and Hanson, W.B., 1993, Gas sorption on coal and measurement of gas content: AAPG Studies in Geology, v. 38, p. 203-218.

\section{Acknowledgements}

This project was completed through the cooperation of project partners that included representatives from industry, environmental consulting, and state and federal government agencies. This group provided NETL with access to data, property, and equipment. 


\section{Disclaimer}

Brand name products described in this manuscript are intended to facilitate understanding and are not endorsed by the United States Department of Energy. 